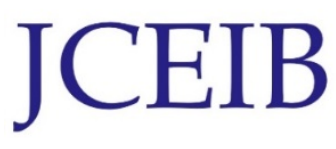

Journal Chemical Engineering and Industrial Biotechnology (JCEIB) Open Access

Volume 2 pp. 68-79; September 2017 CUniversiti Malaysia Pahang Publisher DOI: https://doi.org/10.15282/JCEIB-V2-04.29/9/2017/2.2

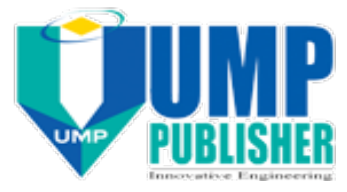

\title{
EFFECT OF TEMPERATURE AND FORMIC ACID CONCENTRATION ON DELIGNIFICATION OF LEUCAENA LEUCOCEPHALA
}

\author{
Nurul Athirah Alwi ${ }^{\mathrm{a}}$, Nor Hanimah Hamidi ${ }^{\mathrm{a}^{*}}$, Noormazlinah Ahmad ${ }^{\mathrm{a}}$, Siti Hajar Noor \\ Shaari $^{\mathrm{a}}$ \\ ${ }^{a}$ Department of Chemical Engineering, Faculty of Chemical \& Natural Resources Engineering, Universiti \\ Malaysia Pahang, Lebuhraya Tun Razak, 24700 Gambang, Kuantan, Pahang \\ *Corresponding author: E-mail: nhanimah@ump.edu.my \\ Tel.: +609-5492869 Fax.: +609-5492888
}

\begin{abstract}
Delignification is essential for wide range of technologies especially in paper industry and ethanol as transportation fuel. Researches have been made by thermal, mechanical, chemical and biology treatment. Recently, L. Leucocephala has been in centre of attraction for paper making industry while formic acid, a typical organosolv system has been given attention by the researchers due to effectiveness on the ability to break down and modify the lignin structure. Hence, delignification of L. Leucocephala was studied using chemical treatment with formic acid. The effect of reaction conditions including reaction temperature and formic acid concentration were investigated at atmospheric pressure for 6 hours of reaction time. Delignification percentage approximately $70-75 \%(\mathrm{v} / \mathrm{w})$ with a pulp yield of $40-62 \%(\mathrm{w} / \mathrm{w})$ was obtained and the optimal reaction temperature is $90^{\circ} \mathrm{C}$ with $90 \%$ of formic acid concentration, respectively. Therefore, temperature and formic acid concentration affected significantly on the delignification process of L. Leucocephala.
\end{abstract}

Keywords: Delignification; Leucaena Leucocephala; formic acid treatment.

\subsection{INTRODUCTION}

Lignocellulose is the most abundant renewable biomass in the world. It considered as major source of 'green' chemicals, biofuels and biobased products (Feria et al., 2012). However, pulp and paper industry experiencing shortages of lignocellulose for raw material as population growth and increase in paper consumption (Lopez et al., 2010 ; Alfaro et al., 2009 ; Malik et al., 2004). Thus, L. Leucocephala has been studied by number of researchers as raw material for high quality paper making (Malik et al., 2004 ; Feria et al., 2012a ; Jiminez et al., 2008). It has been reported that L. Leucocephala harvested high yield of biomass productivity, easily adapting to Mediterranean ecological conditions and short rotation fibres plant (Feria et al., 2012a ; Feria et al., 2012b ; Lopez et al., 2016 ; Lopez et al., 2010 ; Malik et al., 2004). 
Cellulose and hemicellulose are fractions of lignocellulose. They are sugar which can be converted to another products while lignin is a complex natural polymer (Harmsen et al., 2010). Lignin is significantly more difficult to convert to another product compared to cellulose and hemicellulose by hydrolysis process due to the chemical stability conferred by the $\beta(1 \rightarrow 4)$ glycosidic linkages in its structure (Haverty et al., 2012). Naturally, the lignin is degrade by multienzyme process involving hydrolytic and oxidative transformation due to the complexity of lignified plant material (Woolridge, 2014) but this process took a long time for the degradation of lignocelulose. Delignification in industry is focused on the digestibility of constituent sugars but it is challenging due to obstreperous of lignin which may require expensive chemicals and high risk condition (temperature and pressure) to achieve desired reaction rate. The uses of microorganism or purified enzymes in biological way is promising but the process takes place slowly, less drastically, limitation in cultivating temperature and low tolerance to phenolic compound (Chen et al., 2010 ; Pilon et al., 1982). L. Leucocephala was previously delignified by alkaline process with soda and anthraquinone (complex heterogenous reaction process), Kraftt pulping and the most recently acid hydrolysis and pyrolysis process (Feria et al., 2012b ; Feria et al., 2012c ; Loaiza et al., 2017) primarily providing high yield of pulp, low residual lignin , high brightness and good strength properties (Shatalov and Pereira, 2004). Lately, research in the pulp and paper industry has been focused on to ensure sustainable development by using new technologies to improve delignification process.

Recently, formic acid has attracted significant research and commercial interest in paper making industry and bioethanol fuel process as it is an organic solvent and medium for organosolv extraction. Organosolv extraction is recognized as an effective alternative method for delignification as the process using cheap and readily available organic acid for biomass fractionation. Formic acid have similar physical properties with water and being relatively stable it is amenable to recovery and recycling from upstream or downstream operations (Haverty et al., 2012). During formic acid treatment, lignin $\beta-\mathrm{O}-4$ bonds break down and dissolves in the black liquor while hemicellulose convert into mono- and oligosaccharides leaving solid cellulose in the residue. After treatment, formic acid can be recover by distillation (Haverty et al., 2012 ; Zhang et al., 2010).

The objectives are being fulfilled by using formic acid for the delignification of $L$. Leucocephala. The present study include the identification of the lignin content and multilevel structures of lignin in raw and after treatment by using Kappa number method Fourier transform infrared spectroscopy (FTIR) and investigation the optimum conditions of the delignification reaction (reaction temperature and concentration of formic acid) and lignin removal with best condition using formic acid treatment.

\subsection{MATERIALS AND METHODS}

Pod of L. Leucocephala, known as Petai Belalang in Malaysia and Indonesia, were collected from trees by the roadside of Gambang, Pahang area. The pods and seeds were milled to increase the surface area for formic acid treatment. All chemicals used for the treatment and analysis were analytical grade purchased from BT Science Sdn Bhd, Malaysia. 


\section{Kappa Number method}

For the characterization of pods of L. Leucocephala, the following standard analytical procedures were used: Kappa number (TAPPI T 236 om-99 "Kappa number of pulp"), and Kappa number (ES ISO 302:2012 “Pulps-determination of kappa number”).

The bean and pod samples were finely milled in blender between 2.5 to 3 revolutions per minute (rpm) for about 15 minutes. Then, the samples were tested following the standard method and calculation of TAPPI T 236 om-99.

\section{Formic acid treatment conditions}

Oven dried samples were weighed and placed in $250 \mathrm{ml}$ flat-bottom flasks and mixed with formic acid (containing $0.2 \%$ hydrochloric acid $(\mathrm{HCl})$ as a catalyst) at a 10:1 ratio of liquid to solid. The mixture was then incubated in the shaking water bath for 6 hours. The mixture was filtered and washed with formic acid followed by distilled water until neutral $\mathrm{pH}$ was obtained. Afterwards, the samples were oven dried and weighed. The effect of formic acid concentration was analyzed using different concentration of formic acid $(75,80,85$ and $90 \%(\mathrm{v} / \mathrm{v}))$ at $60^{\circ} \mathrm{C}$ for 6 hours. The effect of reaction temperature was investigated at $60^{\circ} \mathrm{C}$, $70^{\circ} \mathrm{C}, 80^{\circ} \mathrm{C}$ and $90^{\circ} \mathrm{C}$ for for 6 hours.

\section{Spectral analysis}

The composition of the pod was determined by using Fourier Transform Infrared Spectroscopy (FTIR). The samples were analyzed in duplicate. Infrared spectra were measured with Thermo Scientific Nicolet IS5 mid FTIR spectrometer. The samples for analysis were in solid state and oven dried then directly analyzed on the plate of the equipment. The spectra were obtained in the absorption band mode in the range of 490 $4000 \mathrm{~cm}^{-1}$. Identification of bands in the infrared spectra was made according to the literature (Tahmasebi et al, 2012 ; Colom et al., 2003).

\section{Determination of kappa number}

\subsection{RESULTS AND DISCUSSION}

Percentage of lignin content and pulp yield in raw pods and seeds of L.Leucocephala were studied using Kappa number standard method. From the percentage of lignin, the concentration of lignin was calculated as in equation 1.

$$
\frac{X}{m}=\frac{P L}{100} \times V_{T}^{2}
$$

Where,

$\mathrm{X}$ : Lignin concentration, $\mathrm{g} / \mathrm{mL}$

PL : Percentage of Lignin, \%

$\mathrm{V}_{\mathrm{T}}$ : Total volume (solution), $\mathrm{mL}$

$\mathrm{m}$ : mass of sample used in Kappa method, $\mathrm{g}$ 
Percentage of lignin content together with lignin concentration were summarized in the Table 1.

Table 1 : Lignin content and concentration in raw pod and seed of L. Leucocephala

\begin{tabular}{|c|c|c|}
\hline SAMPLE & $\begin{array}{c}\text { LIGNIN PERCENTAGE } \\
(\%)\end{array}$ & $\begin{array}{c}\text { LIGNIN } \\
\text { CONCENTRATION } \\
\text { (G/ML) }\end{array}$ \\
\hline Leucocephala pods & $5.16 \pm 0.23$ & $0.0659 \pm 0.016$ \\
\hline Leucocephala seeds & $5.90 \pm 0.57$ & $0.0671 \pm 0.008$ \\
\hline
\end{tabular}

Table 1 shows that lignin percentage in the pod is lower than the seed. After both of empty pod and seed were oven dried, thick coat layer on the surface of the seed was observed whereas empty pod have thin coat layer. The coating layer may contribute to the percentage of lignin as well as percentage of cellulose and hemicellulose in the sample. According to Arora and Joshi, 1985, the lignin percentage in the pod varies from 4.8 to $14.6 \%$ which is lower than the seed which varies from 12.1 to $18.1 \%$ depends on the cultivars due to the thickness of coat.

\section{Effect of formic acid concentration on the percentage lignin removal}

The effect of formic acid concentration on the treatment was investigated using different concentration $(75,80,85$ and $90 \% \mathrm{v} / \mathrm{v})$, respectively. In this study, both pod and seed were treated in different concentrations of formic acid and the result is shown in Figure 1(a). The highest percentage of lignin removal (71\% from pod and $75 \%$ from seed) can be achieved when $90 \%(\mathrm{v} / \mathrm{v})$ of formic acid was used. During formic acid treatment, cellulose, hemicellulose and lignin could be separated based on solubility in acid, organic solvent, water and due to both organic and acidic properties of formic acid. High acid concentration can help break down matter in lignin by cleaves ether bonds between lignin and hemicellulose (Lam et al., 2001; Zhang et al., 2010; Xu et al., 2012). This result complies with some studies which found that higher percentage of lignin removal can be obtained with $90 \%$ concentration of formic acid (Lam et al., 2001; Jahan et al., 2007; Tu et al., 2008). If the concentration of formic acid increased over $90 \%$, pentosanes content and viscosity will remain constant (Lam et al., 2001). 


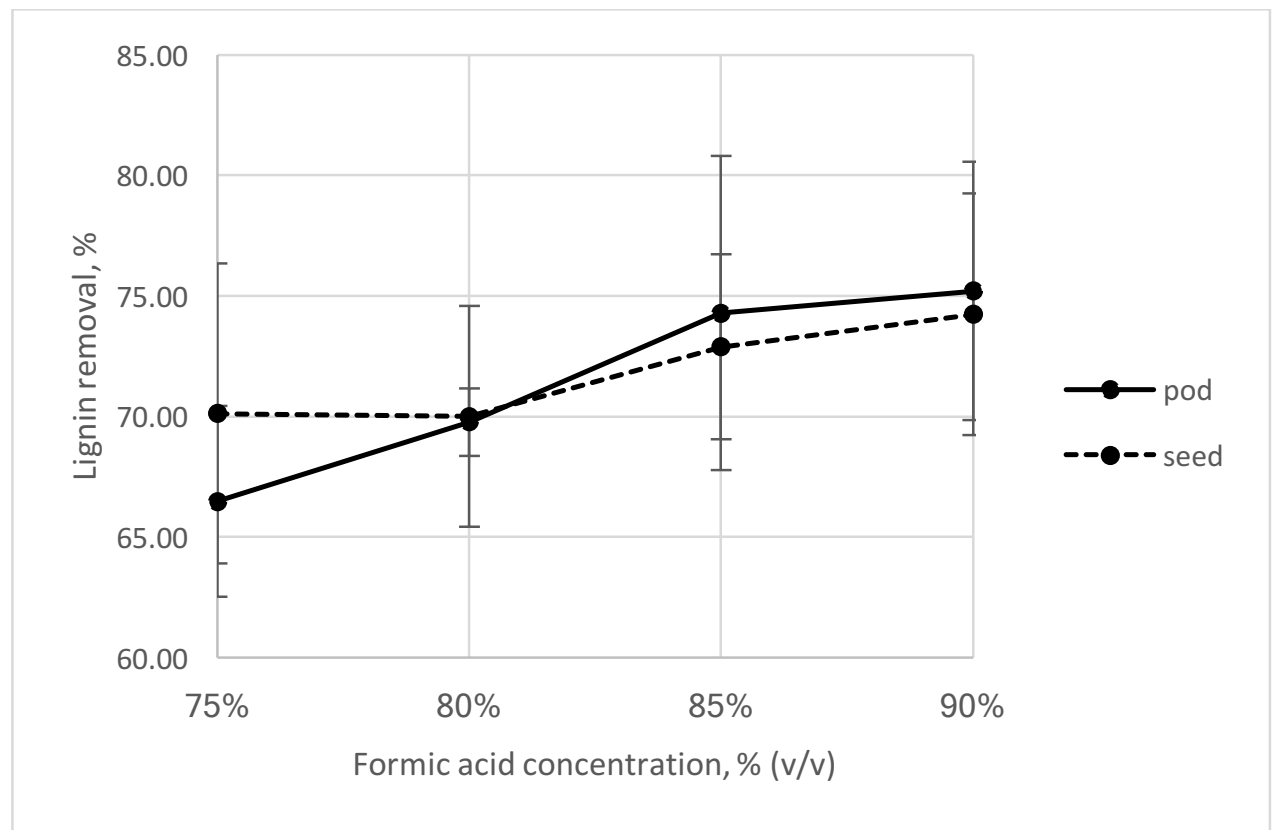

(a)

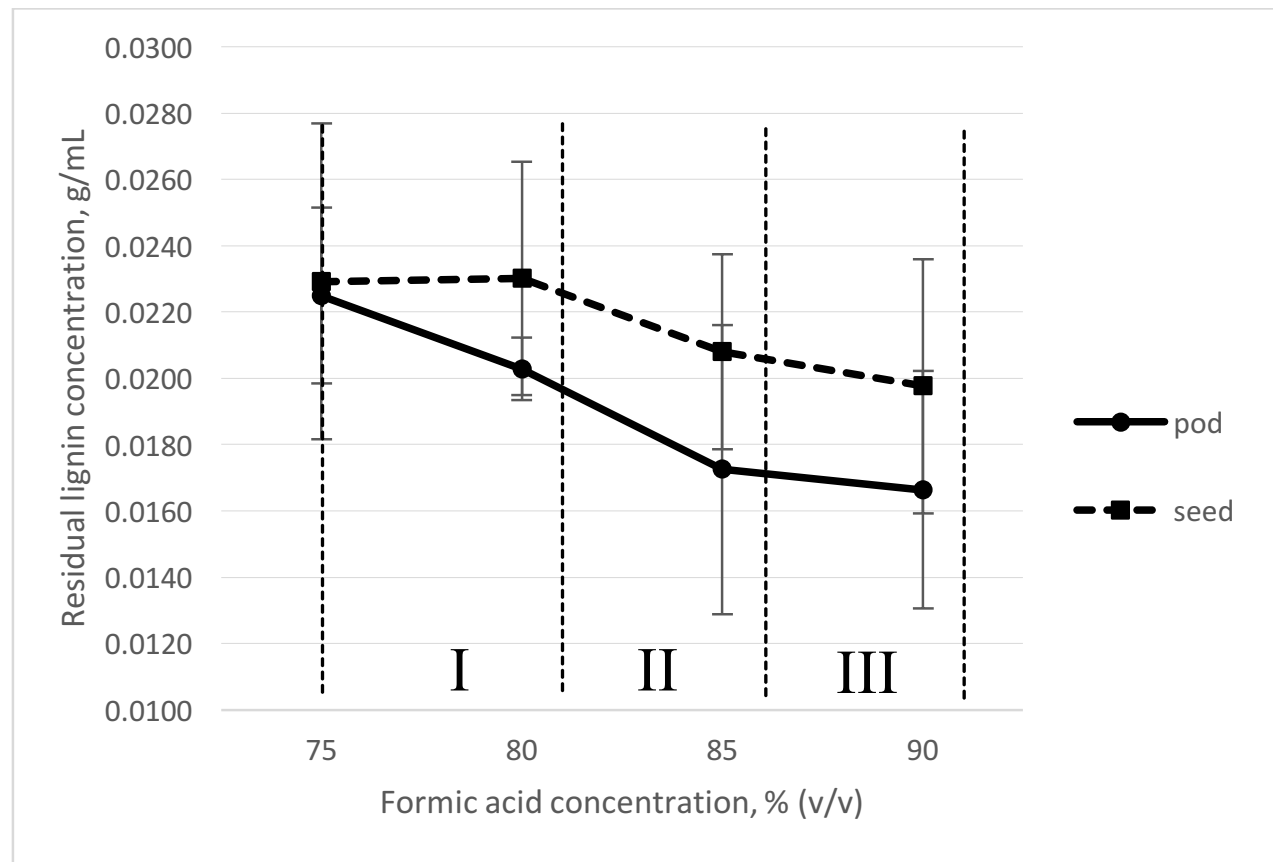

(b)

Figure 1 (a) Effect of formic acid concentration on percentage of lignin removal, and (b) residual lignin concentration from pod and seed of L. Leucocephala

Figure 1(b) presents residual lignin concentration after treated with various formic acid concentration. In the figure, there was significant difference between pods and seeds. The 
residual lignin concentration in pod decreased steadily. Overall, the results can be explained by the chemical reactions underlying the delignification processes. As can be seen from Figure 1(b) the plots have three regions which are part I, II and III. Generally, two types of structural change in lignin which may connected with each other which are degradation by cleavage of certain interunit linkages and introduction of hydrophilic groups (Gierer, 1986). Previous studies conclude that the cleavage of ether linkages is responsible for the degradation of interunit linkages in the process which are involves $\alpha$-ether bonds and $\beta$-aryl ether bonds (McDonough, 1992; Gierer, 1980). In part I, it seemed that formic acid concentration ( 75 to $85 \%$ ) is not high enough to create $\beta$-aryl ether bonds. In this part $\alpha$ ether bonds are likely to be cleavage as the linkages are more easily split, especially in free phenolic hydroxyl group lignin in the para position. Thus, two possible reaction can occur which are formation of quinone methide intermediate and nucleophilic substitution reaction. Figure 2 show the cleavage in $\alpha$-ether bond which lead to formation of quinone methide intermediate and nucleophilic substitution reaction. Further $\beta$-ether cleavage will occur in more strongly acidic systems (part II and III). The possible mechanisms for the cleavage of $\beta$-ether cleavage are formation of $\omega$-guaiacylacetone, Hibbert's ketone followed by $\beta$-ether cleavage and elimination of formaldehyde. Other mechanisms also could be taken place but may be limited by the characteristics of the particular process. In summary, the highly concentrated acid could facilitated $\beta$-ether cleavage but may be limited by solvent-specific reactions (McDonough, 1992).

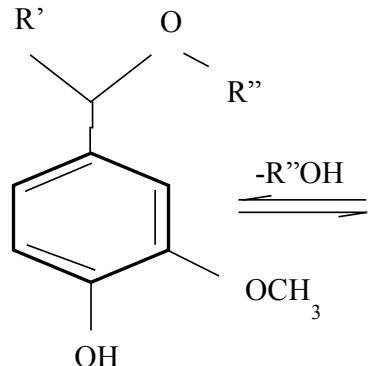

$\mathrm{OH}$

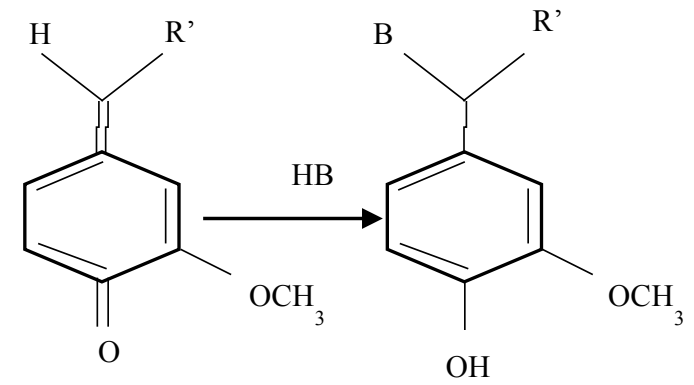

(a)

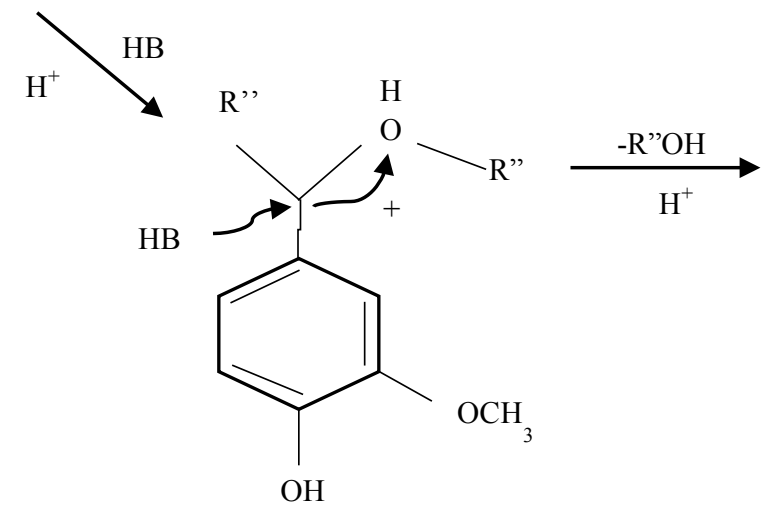

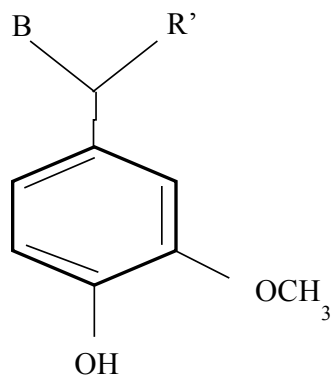

(b)

Figure 2 Solvolytic cleavage of a phenolic $\alpha$-aryl ether linkage via a (a) quinone methide intermediate and (b) nucleophilic substitution 


\section{Effect of reaction temperature on percentage of lignin removal}

In order to determine the effect of temperature on percentage of lignin removal, four different temperatures $\left(60,70,80\right.$ and $\left.90^{\circ} \mathrm{C}\right)$ were studied. The results in Figure 2(a) shows the percentage of lignin removal according to the varied reaction temperature. Formic acid removed 79 and $74 \%$ of lignin in seed and pod respectively at $90^{\circ} \mathrm{C}$. This result differs from fractionating lignocellulose by formic acid (Zhang et al., 2010) using mild condition $\left(60^{\circ} \mathrm{C}\right.$ at atmospheric pressure). This might be due to size of sample used in the treatment and concentration of formic acid. Recovery of lignin obtained under mild condition is $70 \%$ (Zhang et al., 2010) while in this study, recovery of lignin can be achieved up to $79 \%$ when the temperature increased to $90^{\circ} \mathrm{C}$. Increasing the temperatures will reduce lignin content as it speed up plant matter breakdown and exposing lignin structure at high concentration of formic acid. The researchers also state that cooking temperature closely related with the formic acid concentration. The temperature has stronger effect on pulp yield and kappa index as if the temperature is too low will increased contact time while too high temperature reducing contact time to avoid carbohydrate degradation (Lam et al., 2001). A study reported that minimum lignin content and pulp yield can be achieved at $110{ }^{\circ} \mathrm{C}$ and the value are decreasing when the temperatures were increased to 120 and $130{ }^{\circ} \mathrm{C}$ (Dapia et al., 2002). However, the sample was treated with $80 \%$ of formic acid while in this study, $90 \%$ of formic acid was used. Hence, delignification could be neither happen nor stop when the temperature increase up until $100{ }^{\circ} \mathrm{C}$.

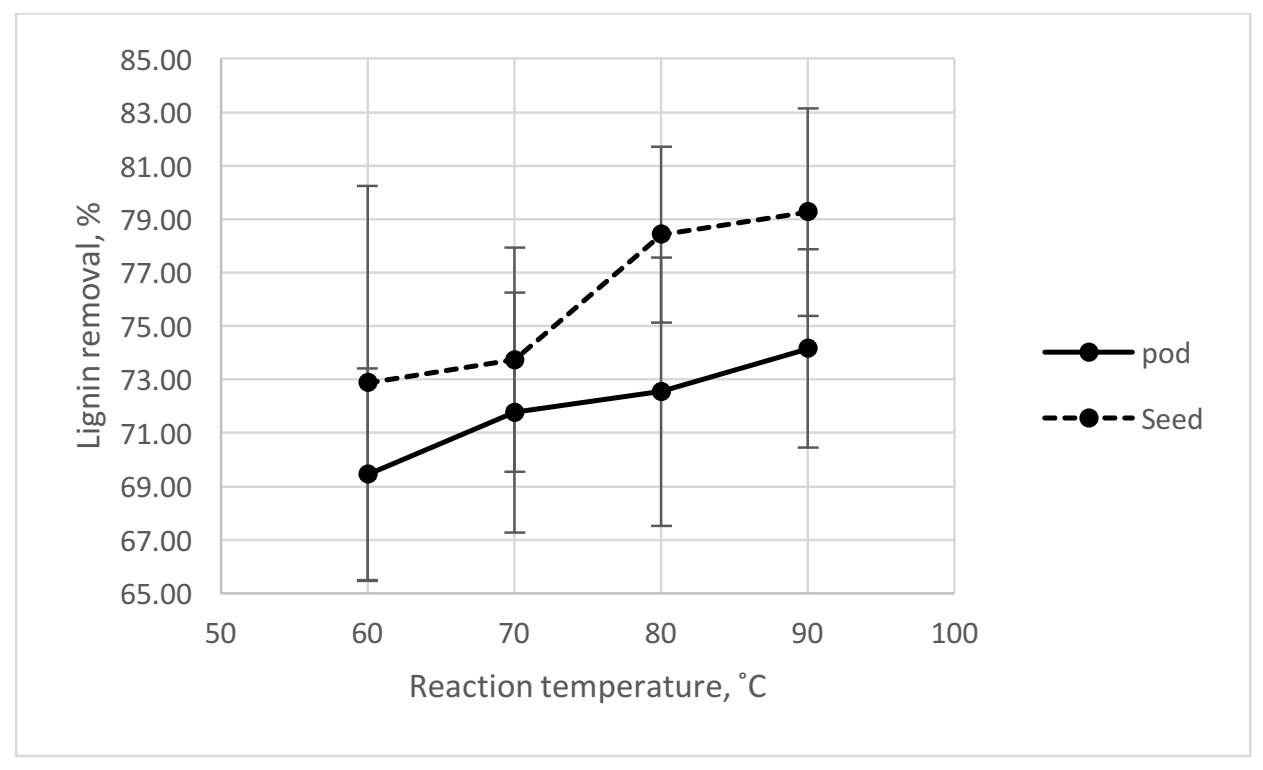

(a) 


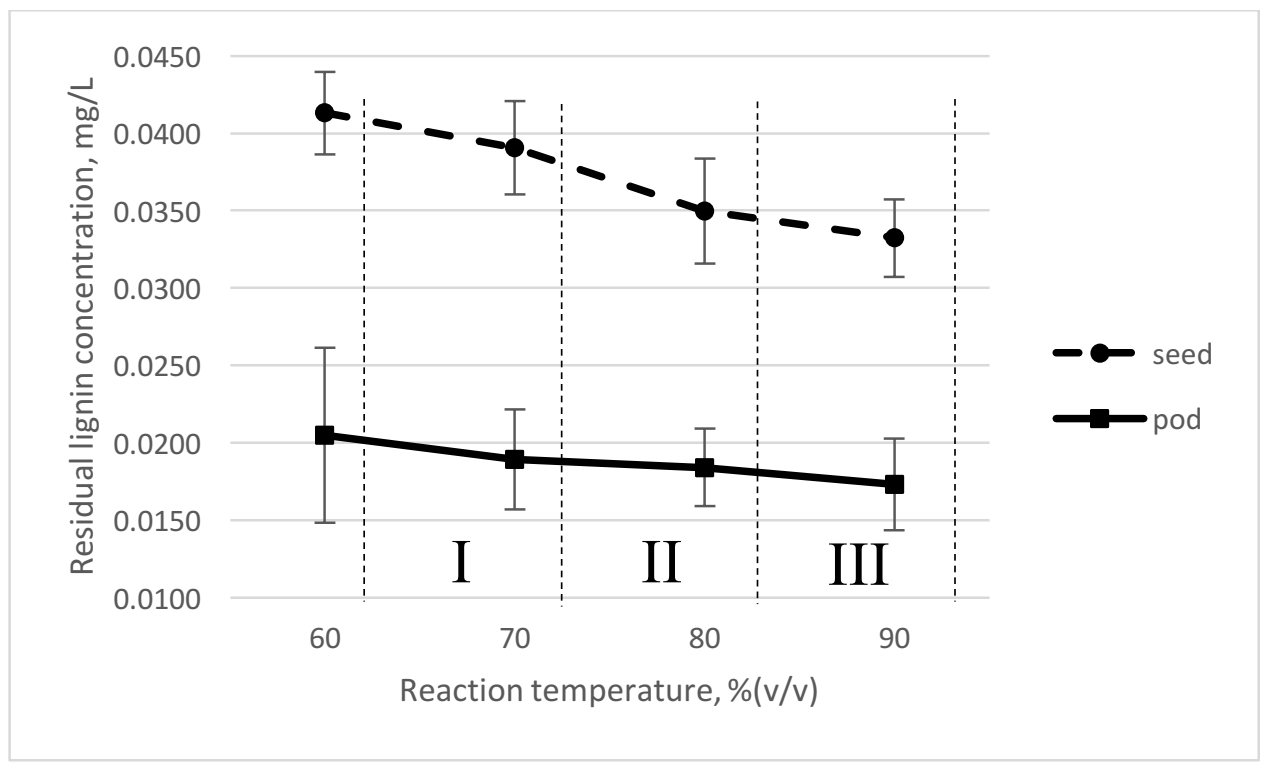

(b)

Figure 3: (a) Effect of reaction temperature on percentage of lignin removal, and (b) residual lignin concentration from pod and seed of L. Leucocephala

Figure 3(b) presents the residual lignin obtained after treated with $90 \%$ of formic acid but in different temperature. The figure above illustrates the breakdown of lignin structure and bond in lignin under different temperature. Lignin is known to be 'hard' and glossy at room temperature but can be "soften" above glass transition temperature (range between 80 and $100{ }^{\circ} \mathrm{C}$ ) (Petridis et al., 2011). Part I is an initial delignification having low activation energy indicates that the rate of the process is diffusion. In this part, cleavage of $\alpha$ - and $\beta$ aryl ether in phenolic lignin structure are likely to be happen predominantly on cleavage of $\alpha$-aryl ether (Gierer, 1986; Gierer, 1985). Part II and III have higher activation energy which is normal for heterolytic chemical reaction. The rate of cleavage of $\alpha$ - and $\beta$-aryl ether linkages in phenolic units is much faster and cleavage of $\alpha$ - and $\beta$ - aryl ether in nonphenolic structure may be considered (Gierer, 1980). When the temperature is increase, Hion in formic acid will have shorter contact time at the site of both phenolic and nonphenolic structure thus, the rate of delignification will decrease (Lam et al., 2001).

\section{FTIR spectra of lignin residues}

FTIR analysis was done to detect delignification activity after been treated with formic acid. Figure 4 shows the FTIR spectra of lignin residue sample before and after the treatment with formic acid and table 2 shows significant differences in the FTIR spectra bands. 


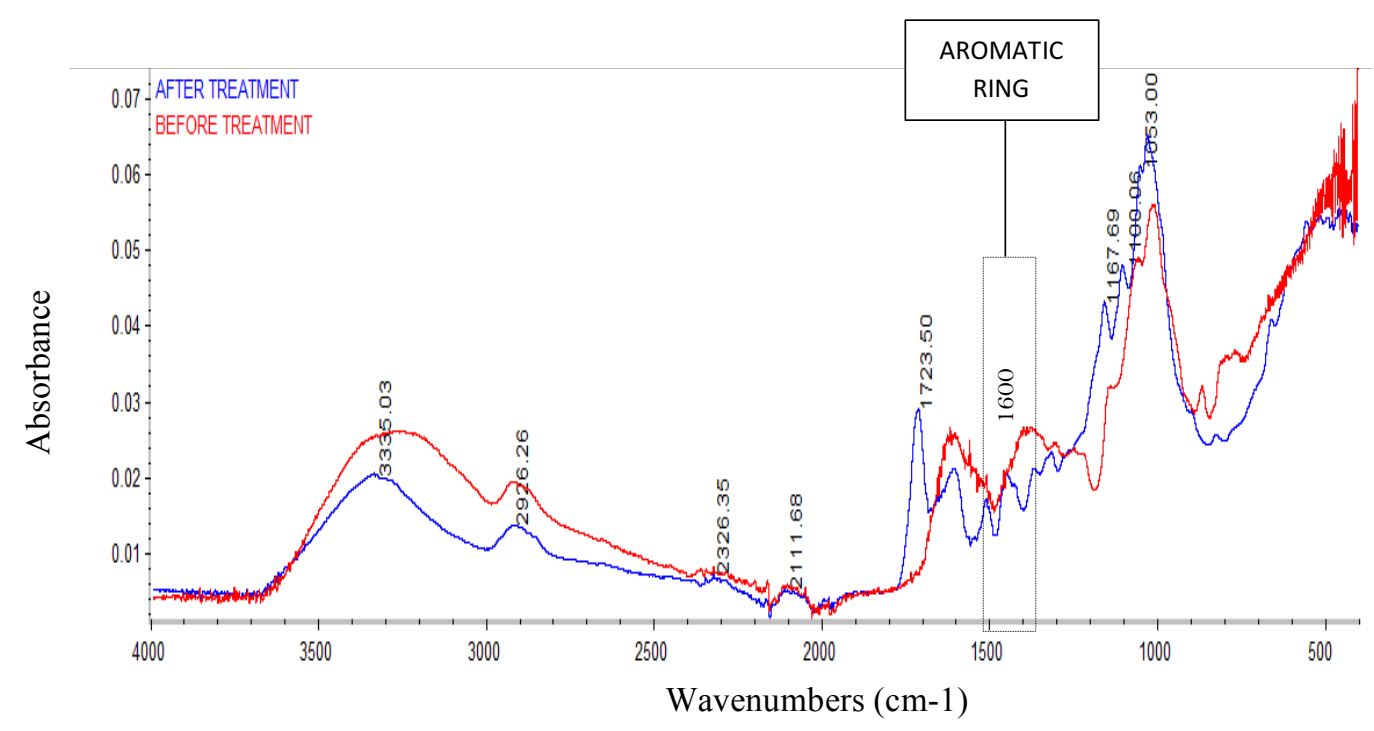

Figure 4: FTIR spectra of lignin residue before and after treatment with formic acid

FTIR analysis as demonstrated in the vibration peak at wavenumbers $3335 \mathrm{~cm}^{-1}$ is attributed to stretch $\mathrm{H}$-bonded, $\mathrm{O}-\mathrm{H}$ in alcoholic or phenolic compound and at $2926 \mathrm{~cm}^{-1}$ is attributed to stretch $\mathrm{C}-\mathrm{H}$ and stretch $\mathrm{O}-\mathrm{H}$ bond in aromatic methoxyl groups and in methyl and methylene groups of side chain. Absorbance value decreasing after the treatment showing that the bond probably break and formed other types of bond through the reaction in the acidic media. New phenolic and enolic structures will formed resulted from reaction of both phenolic $(\mathrm{R}=\mathrm{H})$ and non-phenolic $(\mathrm{R}=$ alkyl or aryl) units in acidic media (Gierer, 1985 ; Gierer, 1986). The band at $1723 \mathrm{~cm}^{-1}$ attributed stretch $\mathrm{C}=\mathrm{O}$ in carbonyl group and stretch acyclic ketone group. Alkyl halide, $\mathrm{C}-\mathrm{N}$ amine, ether and ester group were assigned at 1723,1100 and $1053 \mathrm{~cm}^{-1}$, respectively. Upon analysis, the absorbance value after treatment increasing probably due to the cleavage at $\alpha$-aryl ether and $\beta$-aryl ether and lignin condensation reaction (Mcdonough, 1992). Aromatic ring vibrations bands lies around 1600 and $1500 \mathrm{~cm}^{-1}$ (Coates, 2006). The bands were observed before and after acid treatment showing that some of aromatic ring break after treatment with formic acid. Electrophilic reaction in acidic media opening the aromatic ring through oxidation with hydroxonium ion, $\mathrm{HO}^{+}$as reacting species (Gierer, 1982). Thus, FTIR spectra analysis show significant differences for each bands and reduced absorbance value on selected peaks. 
Table 2 : Absorbance differences of FTIR spectra

\begin{tabular}{|c|c|c|c|c|}
\hline \multirow[t]{2}{*}{$\begin{array}{l}\text { Wavenumber } \\
\qquad\left(\mathrm{cm}^{-1}\right)\end{array}$} & \multirow[t]{2}{*}{ Functional group } & \multicolumn{2}{|c|}{$\begin{array}{c}\text { Spectra } \\
\text { Absorbance (\%) }\end{array}$} & \multirow[t]{2}{*}{ Difference } \\
\hline & & $\begin{array}{c}\text { Before } \\
\text { treatment }\end{array}$ & $\begin{array}{c}\text { After } \\
\text { treatment }\end{array}$ & \\
\hline 3335 & Alcohols, phenols & 0.027 & 0.021 & $(+) 0.006$ \\
\hline 2926 & $\begin{array}{c}\text { Alkanes, } \\
\text { carboxylic acids }\end{array}$ & 0.019 & 0.013 & $(+) 0.006$ \\
\hline 1723 & Aldehydes, & 0.028 & 0.008 & $(-) 0.020$ \\
\hline 1167 & $\begin{array}{l}\text { saturated aliphatic, } \\
\text { esters, ether }\end{array}$ & 0.038 & 0.047 & $(-) 0.009$ \\
\hline 1600 & $\begin{array}{l}\text { Aromatic } \\
\text { compound }\end{array}$ & 0.027 & 0.021 & $(+) 0.006$ \\
\hline 1100 & Amines, alcohols, & 0.050 & 0.060 & $(-) 0.010$ \\
\hline 1053 & $\begin{array}{l}\text { carboxylic acids, } \\
\text { esters and ethers }\end{array}$ & 0.058 & 0.060 & $(-) 0.002$ \\
\hline
\end{tabular}

Positive sign $(+)$ indicates increasing

Negative sign (-) indicates decreasing

\subsection{CONCLUSION}

The present study was designed to determine the effect of formic acid concentration and reaction temperature both physically and chemically toward delignification process. As demonstrated, higher percentage of lignin removal can be achieved in both seed and pod of L. Leucocephala, 74 and $79 \%$ respectively at $90 \%$ (v/v) of formic acid with temperature of $90^{\circ} \mathrm{C}$ for 6 hours. Reaction temperature and formic acid concentration must be high enough to allow cleavage of both $\alpha$ - and $\beta$-aryl ether in lignin structure thus, enhance delignification process. Moreover, FTIR analysis show further comparison between before and after treatment focus on lignin related wavenumbers. This difference shows that breaking the chemical bond of each functional group in lignin chain happened as delignification process. Therefore, delignification process is successful using formic acid affected by the reaction temperature and formic acid concentration of L. Leucocephala. These findings enhance our understanding of best condition to achieve high percentage of L. Leucocephala delignification and the chemistry of delignification in terms of chemical interactions. Further research could usefully explore on other parameters such as reaction time, $\mathrm{pH}$ and size of particle's sample together with chemical analogy during the process.

\section{ACKNOWLEDGEMENT}

This work was done at Laboratory of Chemical Engineering under department of Chemical \& Natural Resources Engineering and funded by internal grant of Universiti Malaysia Pahang. 


\section{REFERENCES}

Alfaro, A., Rivera, A., Perez, A., Yanez, R., Garcia, J.C., Lopez, F., (2009). Integral valorization of two legumes by autohydrolysis and organosolv delignification. Bioresource Technology, 103, 1, 381-388.

Arora, S. K., Joshi, U. N., (1985). Carbohydrate Make Up of Green, Fully Ripened Pods and Seeds of Leucaena Leucocephala. Starch, 37, 4, 109-111.

Chen, S., Zhang, X., Singh, D., Yu, H., \& Yang, X., (2010). Biological pretreatment of lignocellulosics: potential, progress and challenges. Biofuels, 1, 1, 177-199.

Coates, J., (2006). Interpretation of Infrared Spectra, A Practical Approach. Encyclopedia of Analytical Chemistry.

Dapia, S., Santos, V., Parajo, J. C., (2002). Study of formic acid as an agent for biomass fractionation. Biomass \& Bioenergy, 22, 3, $213-221$.

Feria, M.J., Garcia, J.C., Diaz, M.J., Fernandez, M., Lopez, F., (2012a). Biorefinery process for production of paper and oligomers from Leucaena Leucocephala K360 with or without prior autohydrolysis. Bioresource Technology, 126, 64-70.

Feria, M.J., Garcia, J.C.,Perez, A., Gomide, J.L., Colodette, J.L., Lopez, F., (2012b). Process optimization in kraft pulping, bleaching and beating for leucaena diversifolia. Bioresources, 7, 1, 283-297.

Feria, M.J., Alfaro, A., lopez, F., Perez, A., Garcia, J.C., Rivera, A., (2012c). Integral valorization of leucaena diversifolia by hydrothermal and pulp processing. Bioresource Technology, 103, 1, 381-388.

Giere, J., (1980). Chemical Aspect of Kraft Pulping. Wood Science and Technology, 14, 4, 241-266.

Gierer, J., (1985). Chemistry of Delignification. Wood Science and Technology, 19, 4, 289-315.

Gierer, J., (1986). Chemistry of Delignification. Wood Science and Technology, 20, 1, 1-33

Gierer, J., (1982). The Chemistry of Delignification. International Journal of the Biology, Chemistry, Physics, and Technology of Wood, 36, 2, 55-64.

Harmsen, P., Huijgen, W., López, L., \& Bakker, R., (2010). Literature Review of Physical and Chemical Pretreatment Processes for Lignocellulosic Biomass. Food and Biobased Research, (September), 1-49.

Haverty, D., Dussan, K., Piterina, V. A., Leahy, J. J., Hayes, M. H. B., (2012). Autothermal, single-stage, performic acid pretreatment of Miscanthus $x$ giganteus for the rapid fractionation of its biomass components into a lignin/hemicellulose-rich liquor and a cellulase-digestible pulp. Bioresources Technology, 109, 173-177.

Jahan, M. S., Chowdhury, D. A. N., Islam, M. K., (2007). Atmospheric Formic Acid Pulping and TCF Bleaching of dhaincha (Sesbania aculeata), kash (Saccharum spontaneum) and banana stem (Musa Cavendish). Industrial Corps and Products, 26, 3, 324-331

Lam, H. Q., Bigot, Y. L., Delmas, M., Avignon, e. G., (2001). Formic acid pulping of rice straw. Industrial Corps and Products, 14, 3, 65-71.

Loaiza, J.M., Lopez, F., Garcia, M.T., Garcia, J.C., Diaz, M.J., (2017). Biomass valorization by using a sequence of acid hydrolysis and pyrolysis processes. Application to Leucaena Leucocephala. Fuel, 203, 393-402.

Lopez, F., Garcia, J.F., Perez, A., Garcia, M.M., Feria, M.J., Tapias, R., (2012). Leucaena diversofolia a new raw material for paper production by soda-ethanol pulping process. Chemical Engineering Research and Design, 88, 1, 1-9.

Lopez, F., Feria, J.M., Garcia, J.C., Garcia, M.T., Diaz, M.J., (2016). Biorefining of Leucaena Leucocephala. Energy optimization of black liquor and polysaccharide fractions. Cellulose chemistry and technology, 50, 9-10, 1005-1014.

Malik, R.S., Dutt, D., Tyagi, C.H., Jindal, A.K., Lakharia, L.K., (2004). Morphological, anatomical and chemical characteristics of Leucaena leucocephala and its impact on pulp and paper making properties. Journal of Scientific \& Industrial Research, 63, 125-133.

Mcdonough, T. J., (1992). The Chemistry of Organosolv Delignification. Institute of Paper Science and Technology Atlanta, Georgia, 455, 1-17.

Petridis, L., Schulz, R., Smith, J.C., (2011). Simulation analysis of the temperature dependence of lignin structure and dynamics. Journal of American Chemical Society, 133, 50, 20277-20287.

Pilon, L., Barbe, M. C., Desrochers, M., Jurasek, L., \& Neumann, P. J., (1982). Fungal treatment of mechanical pulps - its effect on paper properties. Biotechnology and Bioengineering, 24, 9, 20632076.

Shatalov, A.A., Pereira, H., (2004). Arundo donax L. reed: New perspectives for pulping and bleaching, Part 3: Ethanol reinforced alkaline pulping. TAPPI Journal, 3, 2, 27-31. 
Tu, Q., Fu, S., Zhan, H., Chai, X., Lucia, L. A., (2008). Kinetic modeling of formic acid pulping of baggase. Agricultural and Food Chemistry, 56, 9, 3097-3101.

Woolridge, M. E., (2014). Mixed Enzyme Systems for Delignification of Lignocellulosic Biomass. Catalyst, 4, 1-35.

Xu, W., Miller, S. J., Agrawal, P. K., Jones, C. W., (2012). Depolymerization and Hydrodeoxygenation of Switchgrass Lignin with Formic Acid. Chemical and Sustainable Chemical, 5, 667-675.

Zhang, M., Qi, W., Liu, R., Su, R., Wu, S., He, Z., (2010). Fractionating lignocellulose by formic acid: Characterization of major components. Biomass \& Bioenergy, 34, 525-532. 